\title{
Rentabilitäts- und Wirtschaftlichkeitsrechnungen
}

Die Größe eines Wortes stellt die relative Häufigkeit in den Beiträgen des Heft-Schwerpunktes dar.

\section{Organisation}

\section{Prozesse Switches}

Sicherheitsmaßnahmen

Anwendungen

Bewertung Computing

Tabelle Effektivität

Kollaboration Nerte Arbeit

Tosten IT The speicher IT Nutzen $\mathrm{N}_{\text {Tickets }}$

Zugriffe Infrastruktur Ertrag

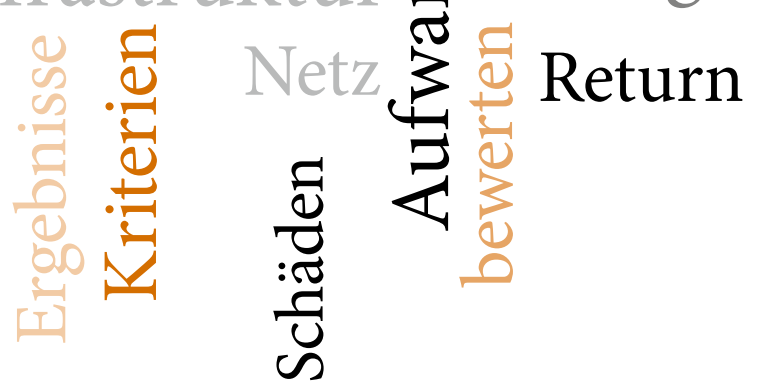

